\title{
Efficiency of Space Heating Systems under the Climate Change
}

\author{
Vladimir Klimenko ${ }^{1}$, Sergey Krasheninnikov ${ }^{2}$, and Ekaterina Fedotova ${ }^{1, *}$ \\ ${ }^{1}$ Moscow Power Engineering Institute, Global Energy Problems Laboratory, 111250 Moscow, Russia \\ ${ }^{2}$ Moscow Power Engineering Institute, Thermal Engineering Department, 111250 Moscow, Russia
}

\begin{abstract}
Impacts of the climate change on the space heating systems are discussed. We have used the latest global temperature data of the Global Climate Historical Network to demonstrate that the heating and cooling demand combined is decreasing in the world regions with boreal and moderate climate conditions almost everywhere. A simulation approach was developed to assess the impact of the climate change of the efficiency of a modern binary-cycle cogeneration power plant. Both statistical parameters of the air temperature and the thermal circuit of the power plant were modeled in details. It was found that even for a quite optimistic climate scenario the annual efficiency decrease may be as high as $1-2 \%$. This means that careful consideration of the climate-related heating load dynamics is of key importance by implementation and renovation of the district heating systems.
\end{abstract}

\section{Introduction}

Decarbonisation of the domestic heating sector remains among the biggest challenges of the mitigation strategies in the moderate climate regions responsible for a significant part of the greenhouse emissions worldwide $[1,2]$. The importance of this problem is quite obvious when remembering that the heating comprises more than a half of the final energy demand in these areas.

\section{Global dynamics of heating demand}

The net change of the space heating and cooling demand remained uncertain for a quite a long time. Nowadays, accumulation of the meteorological observation allows for a definite conclusion.

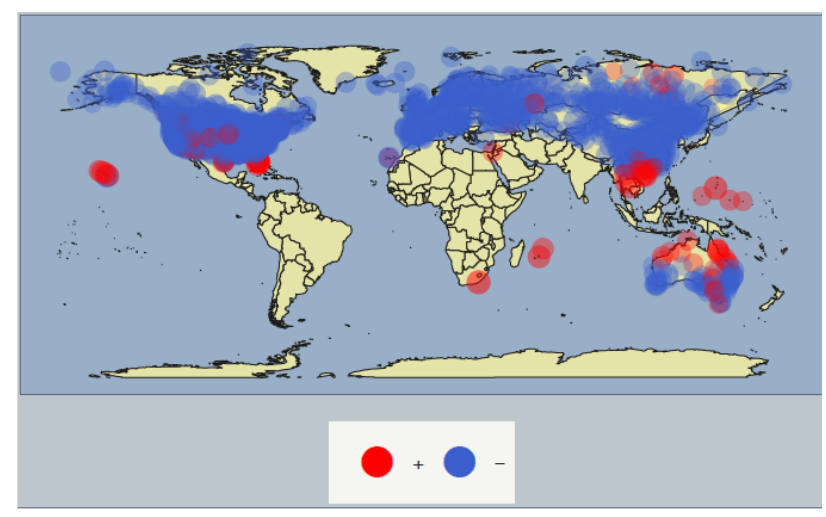

Fig. 1. Net change of the heating and cooling energy demand around the world: change of the annual sum of the heating and the cooling degree-days during 1983-2013 as compared with 1961-1990; red for increase and blue for decrease. Authors' calculations based on GHCN data [8] (assess November 2018).
Research findings of the recent works for Canada, the United States [3], Western Europe [4], China [5] and Russia [6-7] and clearly indicate that the overall household energy demand decreases in the middlelatitude regions and increases in the tropic ones.

We have used the latest data of the Global Climate Historical Network (GHCN) [8] to obtain a global picture. The heating and cooling energy demands were assumed to be proportional to the heating (HDD) and the cooling (CDD) degrees-days respectively, according to the usual practice. The thresholds for the HDD and CDD were assumed to be $18^{\circ} \mathrm{C}$ and $25^{\circ} \mathrm{C}$ respectively in terms of the outdoor temperatures.

The result presented in Fig. 1 is a perfect illustration to the mentioned recent research findings. The overall space heating and cooling demand is increasing in the regions of the boreal and moderate climate zones. Unfortunately, this decrease of the energy demand does not solve automatically the problem of the space heating supply. Moreover, it brings some new challenges.

As we will show below, the climate change may significantly decrease the efficiency of the modern space heating systems. This fact determines crucial importance of an accurate account of the climate-related effects.

\section{Space heating in transition: technological perspective}

The district heating and cogeneration are the most mature technologies which may be used for decarbonisation of the space heating. Today Russia is not among the leaders of decarbonisation policy implementation. However, it seems that an experience accumulated by the Russian district heating systems may

\footnotetext{
* Corresponding author: e.v.kasilova@gmail.com
} 
provide some insights important on the current stage of global development due to the role which the district heating and cogeneration technologies are aimed to play in future energy systems according to mitigation strategies around the world.

Vulnerability of the cogeneration power plants to the change of the load or climate conditions is known [9, 10]. However, there is lack of regional studies of this effect considering the projected climate change. The purpose of the presented work is to develop a simulation approach for filling this gap.

The paper is organised as follows. First we give a brief overview of the cogeneration history in Russia and define a problem for a case study. The next section contains a description of the modelling approaches to assess the actual and future meteorological parameters. Further we will discuss the technical parameters of the cogeneration plant taken for a sensitivity study and present simulation results of its' operation under the current and the future climate conditions. Finally, we give a summary and conclusion of our analysis.

\subsection{Problem definition}

Russia has almost a century-long history of cogeneration use in the district heating sector. It was the end of the nineteen century when Russian engineers started development of the theoretical approaches for use of the power plants to supply domestic consumers with space heating.

The first cogeneration plant began to operate in November 1924 in Leningrad (now Saint- Petersburg). A growth of the cogeneration usage to the national level in 1950s was a result of an accuracy gain of heating demand estimations. Only then the cogeneration became economically advantageous. Afterwards, considerable research and development efforts allowed to achieve high share of cogeneration based district heating systems. Up to the 1990s Russian cogeneration plants were conforming to the international standards by the specific fuel consumption.

The main finding from this long evolution process is that a key prerequisite of the cogeneration plant operation is matching between the actual heating load and the plant parameters. Recent radical changes of the heat load patterns across the country have led to a suboptimal operation of the cogeneration plants in the long term. That has heavily deteriorated efficiency of the plants, determined negative social perception towards the cogeneration and resulted in the dramatic increase of the heat-only boiler plants share in the heating market [11].

The climate change has still resulted in a noticeable decrease of the space heating demand across the Russia. Indeed, it means considerable fuel conservation. But it also means the further changes of the heating demand patterns. The overall effect of this demand decrease on the operation of the district heating systems is still unclear. Our work is intended to be a first step to fulfil this gap.
We have developed a simulation approach to assess impact of the climate change on the efficiency of a modern cogeneration power plant. Below we demonstrate application of this approach considering real meteorological conditions. Saint-Petersburg was considered as an operation site due to following reasons. First of all, the meteorological records for SaintPetersburg are among of the longest ones available for Russia and are of very good quality. Besides, it was Petersburg where the first Russian (and one of the first worldwide) cogeneration power plant was put into operation.

\subsection{Change of the air temperature}

The annual average temperature in Saint-Petersburg has a clear linear increasing trend during the last fifty years. That warming process is associated with the significant decrease of the space heating demand (Fig. 2). This trend is very likely to persist during the whole twenty-first century.

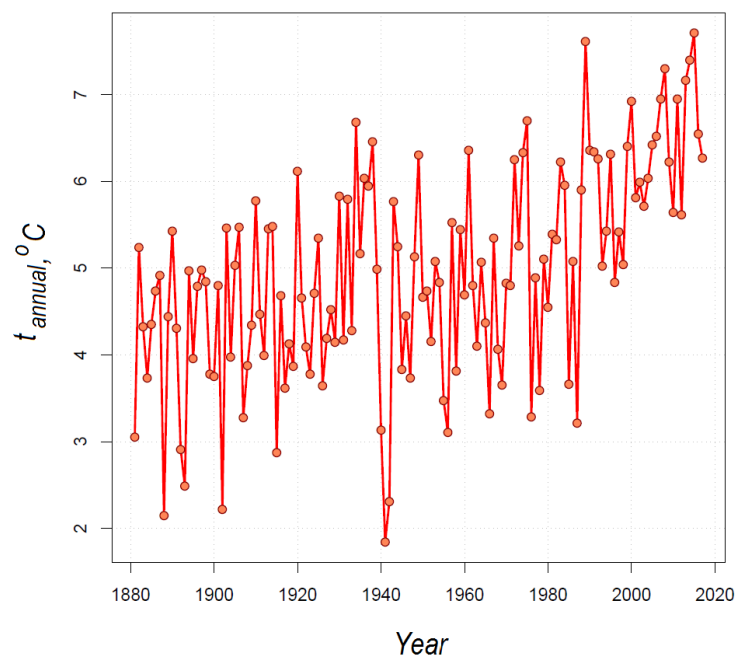

(a)

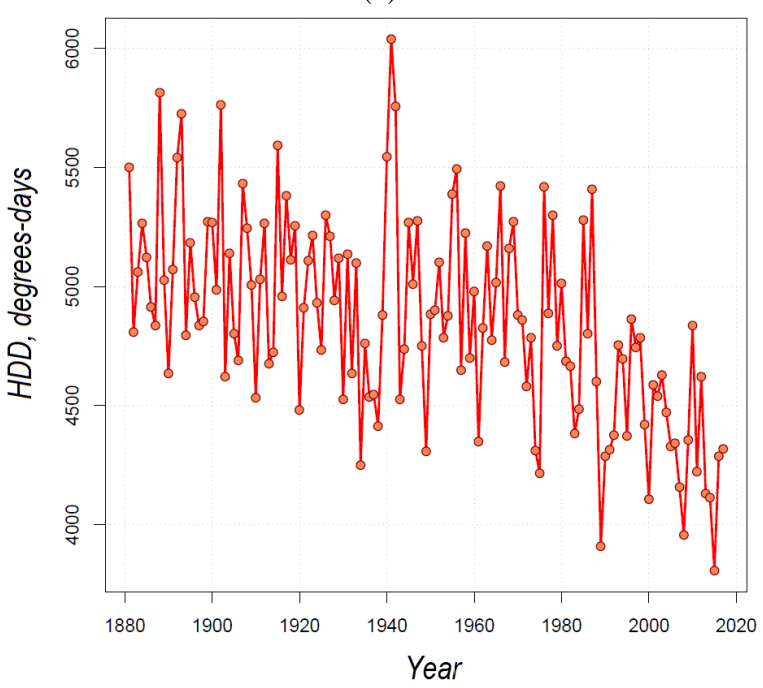

(b)

Fig. 2. Observed changes of the climate conditions in SaintPetersburg: $a-$ annual temperature, $b$ - heating degree-days. Authors calculations based on the Roshydromet data [10]. 


\subsection{Modelling of meteorological conditions}

There is some evidence that the climate change may be manifested in Russia as the increase of the climate variability. That is why detailed study of the air temperature distribution was needed.

We have fulfilled a quantitative assessment of the daily air temperature. The publicity available observation data of the Russian Meteorological Office were used for this analysis [12]. All statistical calculations were implemented by the authors in $\mathrm{R}$ programming environment which is one of the leading modern programming approaches being used for statistical calculations, especially for scientific purposes [13].

A usual normalisation method was applied to the temperature value:

$$
t_{\text {norm }}=(t-\operatorname{mean}(t)) / s d(t)
$$

where $t$ is the observed temperature in Celsius degrees, mean $(t)$ is the mean function, $s d(t)$ is the variance function.

First of all, the data of finest available resolution (of 3-hour observation time step) were used to check longterm changes of the variability. It was found that the variance of the annual temperature distributions don't demonstrates any dramatic changes during the whole observation period including last half of century. Daily temperatures were taken for further analysis due to the fact that daily observation are available on a much longer time span as compared with the hourly ones.

Our final target was to calculate a likely frequency distribution of the daily temperature during the whole year. An influence of the inter-annual variability was smoothed by averaging on the 20 -year intervals.

The next step of our study was definition of the aggregation intervals. The problem was that the annual distribution of the daily temperatures for the whole year has a bi-modal character. Aggregation on the monthtime scale resulted in the high inter-annual variations. The optimal aggregation scales found for the study area were the long warm and long cold periods, that is months from the May to September and from October to the April respectively.

The non-parametric kernel density distribution was found to be quite stable for different 20- years averaging intervals (Fig. 3a). The model estimation of the obtained empiric long warm and long cold period distributions was necessary to construct a projection for further use in the model of the plant.

A distribution of the air temperature is close to normal. However, the real distributions of the daily temperatures are usually more or less asymmetric. Classic asymmetric distributions like gamma distribution are often used to approximate this asymmetry. However, these classic distributions assume that the variable values cannot be negative that clearly is not the case for the normalised temperature, as it may be seen from the formulation (1).
That is why we have applied a less standard approach and used a skewed normal distribution which is a generalization of the normal distribution to a nonsymmetric case [14].

The R-package sn [14-15] was used to fit the annual distribution of the daily temperatures with a skewer normal distribution for the both considered seasons. The modelled distributions for different sets of years were almost the same (Fig. 3b).

Thus, the distribution averaged across the years sets may be a good guess for the future climate conditions. The final result was a number of the hours for each temperature gradation. The modelled distributions matched well with the observations (Fig. 4).

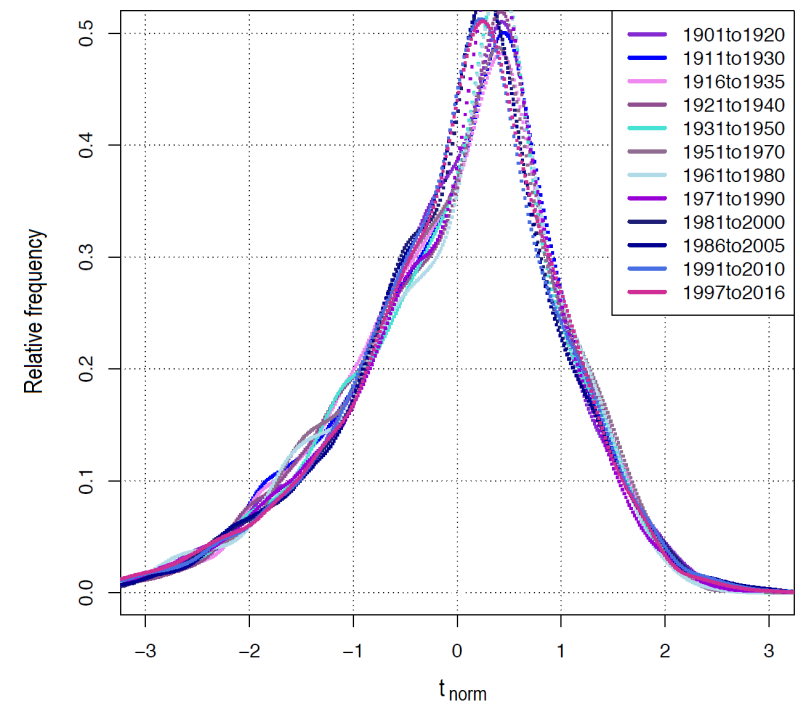

(a)

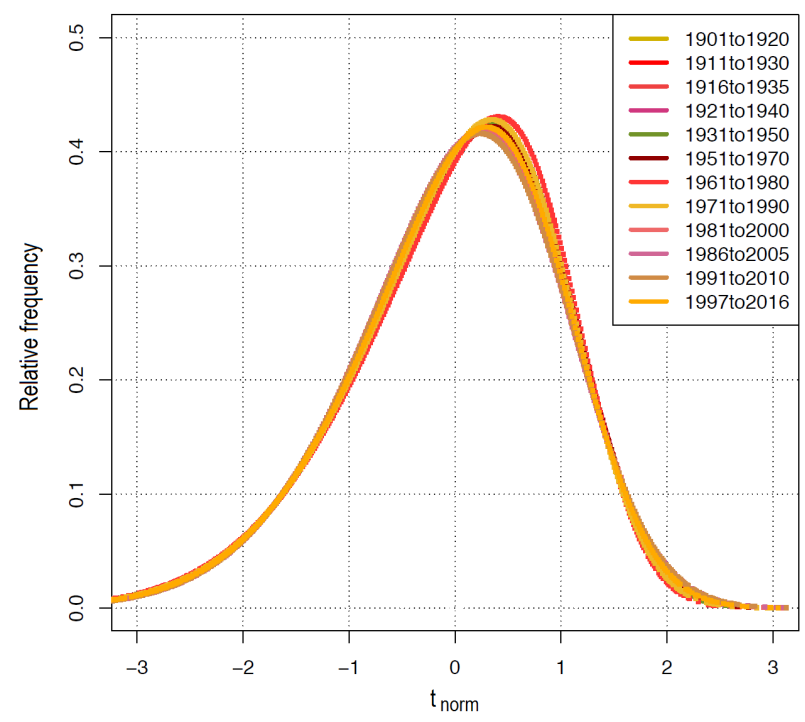

(b)

Fig. 3. Quantification of the daily temperature distribution during the long cold period for a typical year: (a) - kernel density distribution, (b) - modelled skewed normal density distribution. 


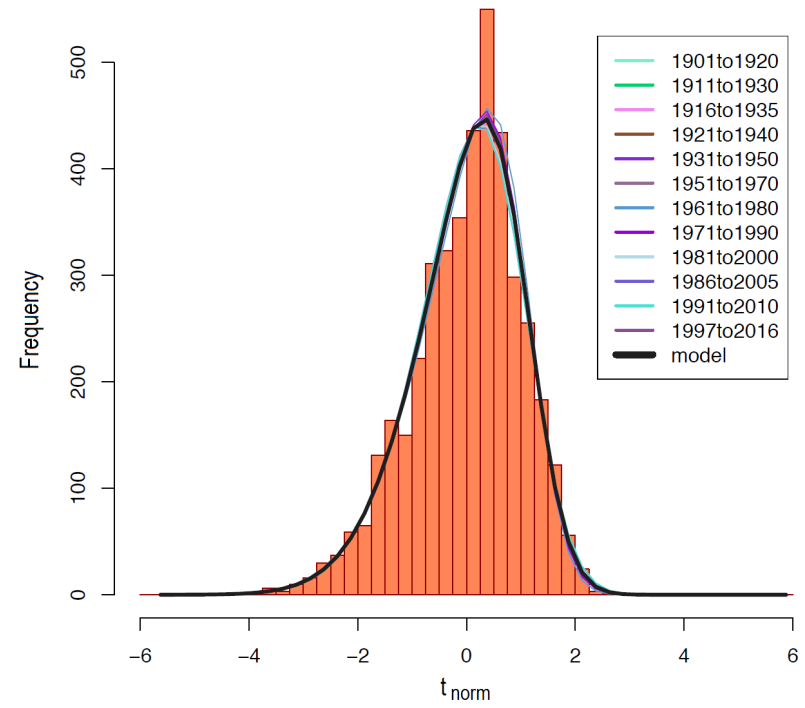

Fig. 4. Simulated frequency distribution compared to the real ones: number of hours for each temperature gradation.

\subsection{Modelling of the cogeneration plant}

A combined-cycle cogeneration power plant was assumed for the further thermal analysis. This kind of power plants is a modern alternative to the power plants of older generation [16]. Replacement of the steamelectric power plants with the combined-cycle ones is the main renovation strategy for gas-fired units. Such a replacement process is going for electricity-only power plants and is one of the leading approaches which likely will be implemented for the next generation cogeneration power systems.

We have assumed the principal diagram with a single-pressure heat recovery boiler (Fig. 5). The exhaust gases of the gas turbine 1 are supplied to the steam recovery steam generator 3 which produces hot steam. The steam drives the steam turbine 2 and is condensed in the condenser. A part of the steam is taken between the low and high pressure steam turbine parts and is supplied to the network heaters 4 .

The real characteristics of modern power equipment were considered for conducting a simulation. The gas turbine 6F.03 (6FA) of General Electric was considered. It represents a machine of $100-\mathrm{MWt}$ class with the nominal efficiency of more than $35 \%$ which is one of the highest among the turbines of this power class. A simulation of the heat and mass balances of the plant was done in the Thermoflow package [17] which is one of the leading modelling tools for power engineering. More details of the thermal analysis may be found elsewhere [18].

An operation of the power plant was simulated assuming the air temperature distribution calculated in the meteorological part of study (Fig. 4) for a typical year for the current and the future climate conditions. The future climate conditions in the considered region were estimated using the climate model developed in the Global Energy Problems Laboratory of the Moscow Power Engineering Institute. The details of this estimation were discussed in [7]. The time horizon for the prospective climate was assumed at about 2070. A selected climate scenario was a optimistic one close to the representative concentration pathway 4.5 [1].

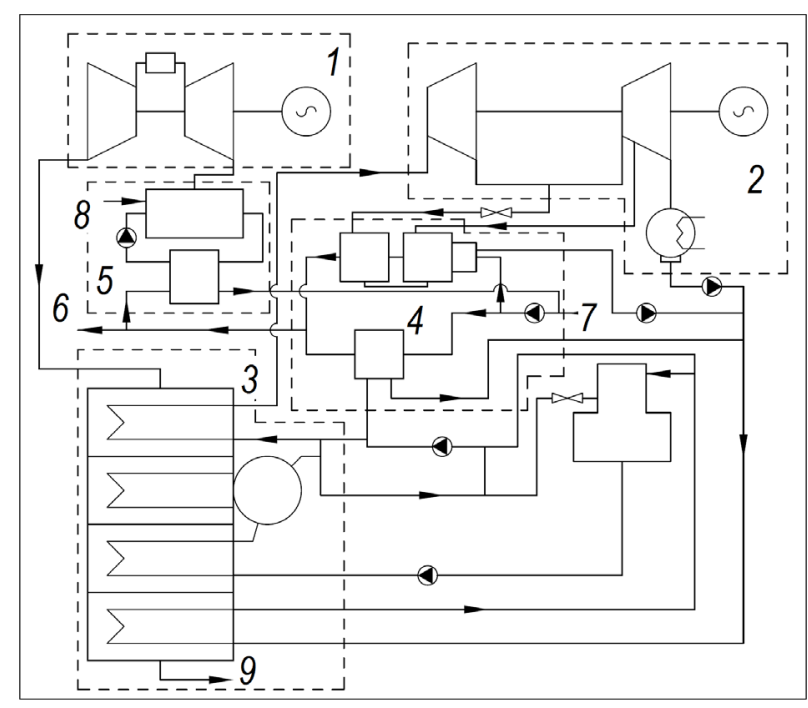

Fig. 5. Principal diagram of the considered cogeneration power plant: 1 - Gas Turbine, 2 - Steam Turbine, 3 - Heat Recovery Steam Generation, 4 - District Heaters, 5 - Anti-Ice System, 6 - Water Sink, 7 - Water Source, 8 - Air Source, 9 Stack.

It was assumed that the power plant supplies to the consumers the heated water which is used both for heating and as the domestic warm water. The temperature of the network water in the supplying pipeline is adjusted according to the change of the annual air temperature during the heating season and is kept $70^{\circ} \mathrm{C}$ when the weather is warm.

\subsection{Results and discussion}

The modelling results for the considered power plant are presented on Fig. 6 and in Table 1.

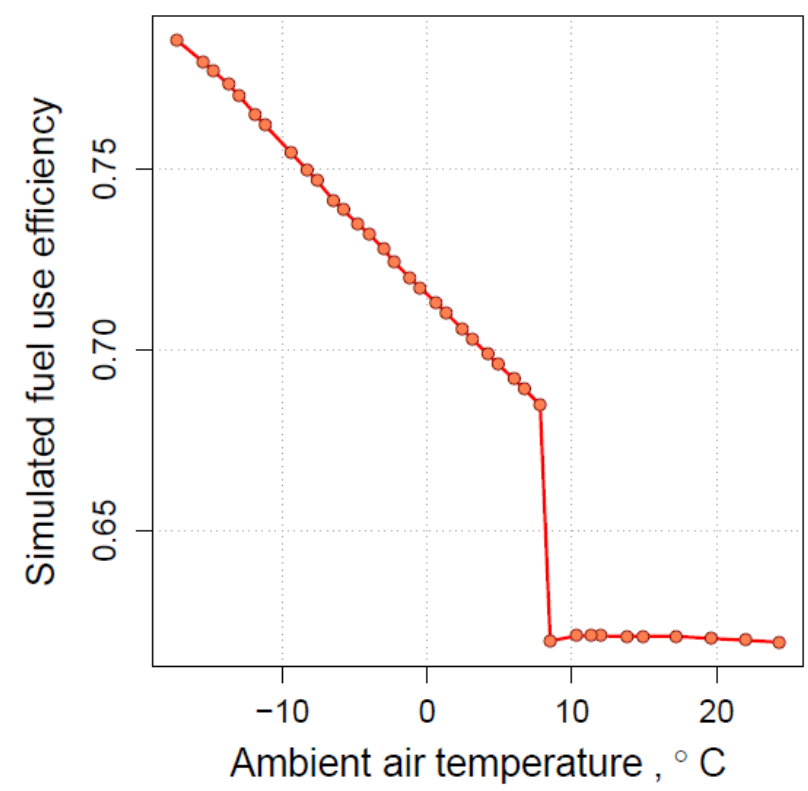

Fig. 6. Sensitivity of the fuel use efficiency of the cogeneration power plant to the ambient air temperature. 
The main outputs are as follows: $E$ is the electrical energy generated by the unit, $Q$ is the heat supplied to the consumer, $E_{f u e}$ is the primary energy of the burned fuel, $\eta$ is the average efficiency of the fuel use:

$$
E f f=(E+Q) / E_{\text {fuel }}
$$

Table 1. Simulation results for operation of the cogeneration plant for the average year under different climate conditions

\begin{tabular}{|c|c|c|c|c|}
\hline & $\begin{array}{c}\mathbf{E} \\
{[\mathrm{GW} h]}\end{array}$ & $\begin{array}{c}\mathbf{Q} \\
{[\mathrm{GW} \mathrm{h}]}\end{array}$ & $\begin{array}{c}\mathbf{E}_{\text {fuel }} \\
{[\mathrm{GW} \mathrm{h}]}\end{array}$ & $\begin{array}{c}\text { Eff } \\
{[\%]}\end{array}$ \\
\hline $\begin{array}{c}\text { Actual } \\
\text { conditions, } \\
\text { cold } \\
\text { period }\end{array}$ & 533.7 & 266.7 & 1108.1 & $\mathbf{7 2 . 2}$ \\
\hline $\begin{array}{c}\text { Projection, } \\
\text { cold } \\
\text { period }\end{array}$ & 540.0 & 242.7 & 1107.9 & $\mathbf{7 0 . 6}$ \\
\hline $\begin{array}{c}\text { Actual } \\
\text { conditions, } \\
\text { whole year }\end{array}$ & 943.5 & 326.3 & 1888.8 & $\mathbf{6 7 . 2}$ \\
\hline $\begin{array}{c}\text { Projection, } \\
\text { whole year }\end{array}$ & 938.3 & 355.6 & 1893.5 & $\mathbf{6 8 . 3}$ \\
\hline
\end{tabular}

The main output of our simulation analysis is quite a significant deterioration of the fuel efficiency use: the decrease is as high as 1.6 percent points for the cold period and 1.1 percent points for the whole year.

\section{Conclusion}

We have developed a simulation approach to assess the impact of the climate change of the efficiency of a modern binary-cycle cogeneration power plant and carried out a detailed analysis for a selected study region. The following lessons may be studied using the presented work:

1. It has been demonstrated using the latest global temperature GHCN archive that the climate change results in the overall decrease space heating and cooling demand in the regions with the boreal and moderate climate.

2. This net-energy benefit means some new challenges for the efficient operation of the cogeneration power units. The effect on the average annual efficiency decrease due to the climate warming may be as high as 1-2 percent points to the end of $21^{\text {st }}$ century even for moderate scenarios.

3. A careful analysis of the prospective heating loads under the climate change is of key importance for the successful implementation of the cogeneration systems under the changing climate conditions in the twentyfirst century.

This work was supported by the Russian Science Foundation (project no. 18-79-10255). The authors are particularly grateful to Dr. hab. A.G. Tereshin for discussions of operation of the Russian district heating systems.

\section{References}

1. IPCC, Climate Change 2013: The Physical Science Basis. Contribution of Working Group I to the Fifth Assessment Report of the Intergovernmental Panel on Climate Change [Stocker, T.F., D. Qin, G.-K. Plattner, M. Tignor, S.K. Allen, J. Boschung, A. Nauels, Y. Xia, V. Bex and P.M. Midgley (eds.)] (2013)

2. F. Ausfelder, M. Fischedick, W. Münch, J. Sauer, M. Themann et al. Schriftenreihe Energiesysteme der Zukunft. November (2017) (in German)

3. Y. Petri, K. Caldeira. Scientific Reports 512427 (2015)

4. J. Spinoni, J. Vogt and P. Barbosa Int. J. Climatol. 35 (2015)

5. Y. Shi1, X. Gao, Y. Xu, F. Giorgi, D. Chen Clim. Res. 67 (2016)

6. V.V. Klimenko, A.V. Klimenko, A.G. Tereshin, D.S. Beznosova, T.N. Andreychenko Therm. Eng. 59 (2012)

7. V.V. Klimenko, E.V. Fedotova, A.G. Tereshin Energy 142 (2018)

8. Menne, M.J., I. Durre, B. Korzeniewski, S. McNeal, K. Thomas, X. Yin, S. Anthony, R. Ray, R.S. Vose, B.E.Gleason, and T.G. Houston GHCNDaily, Version 3. NOAA National Climatic Data Center. http://doi.org/10.7289/V5D21VHZ [access November 2018]

9. I. Andric, N. Gomes, A. Pina, P. Ferrão, J. Fournier, B. Lacarrière, O. Le Corre Energy and Buildings 126 (2016) 77-93

10. N.L. Truong, A. Dodoo, L. Gustavsson Energy 142 (2018)

11. S.P. Filippov, M. D. Dilman Therm. Eng. 65 (2018)

12. O.N. Bulygina, V.N. Razuvaev Daily Temperature and Precipitation Data for 518 Russian Meteorological Stations http://meteo.ru/data [access September (2018)]

13. R Core Team https://www.R-project.org/ (2018)

14. A. Azzalini, A. Capitanio IMS Monographs series. (2014)

15. A. Azzalini The $\mathrm{R}$ package sn'http:// azzalini.stat.unipd.it/SN (2018)

16. R. Bartnik, Z. Buryn J. of Power Technol. 95 (2015)

17. E. Jeffs Turbomachinery Intern. 44 (2003).

18. S.M. Krasheninnikov $\mathrm{PhD}$ Dissertation (in preparation) 